Ambiente \& Água - An Interdisciplinary Journal of Applied Science
ISSN 1980-993X - doi:10.4136/1980-993X
www.ambi-agua.net
E-mail: ambi-agua@agro.unitau.br

\title{
A tecnologia de remoção de fósforo: gerenciamento do elemento em resíduos industriais
}

\author{
doi: 10.4136/ambi-agua.1403
}

Received: 27 May 2014; Accepted: 14 Aug. 2014

\author{
Mariana Manzoni Maroneze ${ }^{1}$; Leila Queiroz Zepka ${ }^{1}$; Juliana Guerra Vieira ${ }^{2}$; \\ Maria Isabel Queiroz ${ }^{2}$ Eduardo Jacob-Lopes ${ }^{1 *}$ \\ ${ }^{1}$ Universidade Federal de Santa Maria (UFSM), Santa Maria, RS, Brasil \\ Departamento de Tecnologia e Ciência de Alimentos \\ ${ }^{2}$ Universidade Federal do Rio Grande (FURG), Rio Grande, RS, Brasil \\ Escola de Química e Alimentos \\ *Autor correspondente: e-mail: jacoblopes@pq.cnpq.br, \\ mariana_maroneze@hotmail.com,lqz@pq.cnpq.br,juguerravieira@uol.com.br, \\ queirozmariaisabel@gmail.com
}

\section{RESUMO}

As elevadas concentrações de fósforo em águas residuárias industriais é uma das principais causas da eutrofização de corpos hídricos receptores, havendo em virtude disto, uma crescente preocupação com o gerenciamento das cargas de fósforo dos efluentes industriais. Além dos aspectos de contenção ambiental, é estrategicamente desejável que os processos de tratamento permitam a recuperação e o reúso deste elemento que é considerado de elevada demanda biológica. Neste sentido, esta revisão objetiva descrever e analisar criticamente o estado atual das tecnologias de gerenciamento de fósforo em águas residuais industriais, com ênfase no reúso do elemento. As tecnologias consideradas incluem abordagens químicas (precipitação química e adsorção), biológicas (sistemas bacterianos, uso macroalgas e microalgas) além de técnicas de fertirrigação.

Palavras-chave: espécies fosforadas, eutrofização, tecnologias de tratamento, reuso.

\section{Phosphorus removal technology: Management of the element in industrial waste}

\begin{abstract}
High phosphorus concentrations in industrial wastewaters is one of the main causes of the eutrophication of water bodies, leading to a growing concern with the management of phosphorus loads from industrial wastewaters. In addition to the environmental aspects of containment, it is strategically desirable that the treatment processes enable the recovery and reuse of this element, which is considered to be of high biological demand. For these reasons, this review describes and critically analyzes the current state of phosphorus management technologies for industrial wastewaters, with emphasis on the reuse of the element. The
\end{abstract}


technologies considered include chemical approaches (chemical precipitation and adsorption), biological (bacterial systems, microalgae and macroalgae) plus fertigation techniques.

Keywords: phosphorus species, eutrophication, treatment technologies, reuse.

\section{INTRODUÇÃO}

O lançamento inadequado de águas residuárias com elevadas concentrações de fósforo em corpos hídricos receptores está vinculado a uma série de alterações ambientais, econômicas e sociais como resultado da eutrofização dos ecossistemas. Estas alterações estão relacionadas com o aumento significativo dos custos de purificação de água potável, a mortes de espécies aquáticas pela desoxigenação da água, a riscos para a saúde humana em função de toxinas produzidas por microalgas, além da constante ameaça para a diminuição da água doce em uma escala global (Majed et al., 2012).

Apesar do fósforo possuir elevado potencial poluidor, está entre os elementos químicos listados como essenciais para os seres vivos. Sua função essencial inicia como constituinte das membranas celulares, participando de inúmeros processos metabólicos. Dentro da célula, encontra-se ligado a moléculas que participam dos fundamentais processos ligados a bioenergética celular. O fósforo é também o centro de armazenamento e processamento de informação genética, fazendo parte das moléculas de RNA e DNA. Desta forma, atua na integridade e reprodução, transporte de nutrientes, metabolismo energético e regulação de processos metabólicos essenciais. Em virtude dessas considerações, o fósforo é um elemento de elevada demanda biológica, o que o torna limitante na natureza (Elser, 2012).

Estimativas apontam que o fósforo é o $13^{\circ}$ elemento mais abundante no universo, embora sua concentração na crosta terrestre seja relativamente baixa, uma vez que suas frações estão geralmente imobilizadas em rochas. De acordo com Cordell et al. (2009), as reservas de fósforo em rochas poderão ser esgotadas nos próximos 100 anos, devido ao massivo uso como insumo industrial em setores de produção de fertilizantes, explosivos, pesticidas e detergentes. Como função desta limitada disponibilidade no período de 2007-2008, os fertilizantes tiveram um aumento nas cotações de $700 \%$, demonstrando o desequilíbrio entre oferta e demanda pelo elemento.

A atividade agroindustrial é uma importante geradora de fósforo nas suas diferentes especiações, o que inclui espécies reativas, ácido-hidrolisáveis e orgânicas tanto na forma dissolvida quanto suspensa. As matérias-primas não incorporadas no produto final ocasionam invariavelmente a geração de águas residuárias com substanciais concentrações de fósforo. Em geral, os efluentes agroindustriais apresentam composição de fósforo total variando entre 1 a $300 \mathrm{~g} \mathrm{~m}^{-3}$. O Conselho Nacional do Meio Ambiente (CONAMA), por meio da Resolução 357 de 17 de março de 2005, estabelece padrões de emissão de fósforo, além de permitir que os órgãos ambientais estaduais adotem valores mais restritivos (Brasil, 2005). Essa resolução indica que os valores máximos tolerados de emissão variam de 1 a $4 \mathrm{~g} \mathrm{~m}^{-3}$ em função da vazão de geração industrial.

Tecnologicamente, o gerenciamento desse constituinte das águas residuárias agroindustriais não está completamente estabelecido. As tecnologias em escala industrial disponíveis atualmente são questionáveis e algumas tecnologias emergentes potenciais ainda não possuem maturidade necessária para o escalonamento. As principais tecnologias incluem abordagens químicas (precipitação química e adsorção), biológicas (sistemas bacterianos, uso macroalgas e microalgas) além de técnicas de fertirrigação.

Finalmente, o reúso do elemento no sentido da valorização dos resíduos agroindustriais é considerado a fronteira do conhecimento dos sistemas emergentes de tratamento. Dentro desta abordagem, o fósforo torna-se um recurso renovável passível de exploração tecnológica. Entre 
as variadas aplicações inclui-se o uso como insumo na produção de fertilizantes, aditivo de rações animais além da manufatura de produtos de alto valor agregado. Em face disto o objetivo desta revisão é descrever e analisar criticamente o estado atual das tecnologias de gerenciamento de fósforo em águas residuais industriais, com ênfase no reúso do elemento.

\subsection{Precipitação química de fósforo}

A tecnologia de precipitação química de fósforo vem sendo aplicada há aproximadamente 70 anos. A precipitação química em efluentes envolve a adição de um sal de um metal bivalente ou trivalente, causando a precipitação de um fosfato de metal insolúvel, que é separado por sedimentação (Rittmann et al., 2011). A tecnologia de precipitação química de fósforo é bastante flexível e pode ser aplicada nos diversos estágios do tratamento de efluentes, podendo consistir em uma precipitação primária, secundária ou terciária.

Entre as principais vantagens da precipitação química de fósforo, citam-se a agilidade do processo, a facilidade de controle operacional, tolerância a compostos biologicamente tóxicos, e independência da temperatura da reação (Morse et al., 1998). É atualmente uma das tecnologias de maior emprego industrial, embora a elevada demanda por insumos químicos e a produção de lodos com altas concentrações de metais pesados onerem substancialmente o processo (Pratt et al., 2012).

Os sais de maior aplicabilidade para esta finalidade são a base de íons de $\mathrm{Fe}, \mathrm{Al}, \mathrm{Ca}$ e $\mathrm{Mg}$, sendo a escolha uma função da eficiência de remoção, associada à qualidade do lodo formado (Szögi, et al., 2006). Os equipamentos usados, nesta tecnologia, consistem geralmente em reatores químicos de mistura perfeita.

\subsection{Precipitação de fósforo com ferro e alumínio}

Os sais de ferro e alumínio são os mais utilizados atualmente para a precipitação do fosfato em virtude do custo. Os compostos mais utilizados são $\mathrm{FeCl}_{3}, \mathrm{Fe}_{2}\left(\mathrm{SO}_{4}\right)_{3}, \mathrm{FeSO}_{4} \mathrm{e}$ $\mathrm{Al}_{2}\left(\mathrm{SO}_{4}\right)_{3}$.

Genericamente, a Equação 1 representa esquematicamente à formação dos precipitados a base de ferro ou alumínio (Tchobanoglous et al., 2003), evidenciando que os fosfatos capturados estarão ligados aos sais metálicos:

$$
\mathrm{X}^{3+}+\mathrm{H}_{n} \mathrm{PO}_{4}^{3-n} \rightarrow \mathrm{XPO}_{4}+n \mathrm{H}^{-}
$$

em que:

\section{$\mathrm{X}=\mathrm{Fe}$ ou $\mathrm{Al}$}

Com relação às eficiências do processo, remoções de até $95 \%$ são comumente relatadas. Independente destes elevados desempenhos, o lodo produzido é de difícil reúso, sendo normalmente descartado como resíduo sólido industrial em aterros sanitários controlados, havendo severas limitações com respeito à contaminação de águas subterrâneas (Fytianos et al., 1998; Özacar and Şengil, 2003).

\subsection{Precipitação de fósforo com cálcio}

A precipitação de fósforo utilizando cálcio é uma alternativa aos elementos anteriormente considerados. O baixo custo dos insumos, associado à facilidade de manuseio são consideradas as principais melhorias desta técnica. O hidróxido de cálcio é a principal forma reagente de uso industrial (De-Bashan e Bashan, 2004). A formação dos precipitados a base de cálcio é genericamente representada pela Equação 2:

$$
10 \mathrm{Ca}^{2+}+6 \mathrm{PO}_{4}^{3-}+2 \mathrm{OH}^{-} \leftrightarrow \mathrm{Ca}_{10}\left(\mathrm{PO}_{4}\right)_{6}(\mathrm{OH})_{2}
$$


Estequiometricamente, o hidróxido de cálcio é adicionado ao efluente, reagindo com a alcalinidade natural do bicarbonato para precipitar $\mathrm{CaCO}_{3}$. À medida que o valor do $\mathrm{pH}$ aumenta, os íons de cálcio em excesso, reagem com o fosfato, precipitando um composto chamado de hidroxiapatita $\left[\mathrm{Ca}_{10}\left(\mathrm{PO}_{4}\right)_{6}(\mathrm{OH})_{2}\right]$.

Além da remoção de fósforo, o cálcio pode atuar na clarificação do efluente, se este possuir material particulado e condições de $\mathrm{pH}$ e alcalinidade adequadas (Rittmann et al., 2011). Outro fato de interesse no uso de cálcio para a precipitação química de fósforo é o grande interesse comercial das indústrias de fertilizantes nos fosfatos de cálcios precipitados.

As eficiências de remoção podem alcançar $95 \%$, embora a precipitação de fósforo com cálcio normalmente apresente menores eficiências quando comparadas com o uso do ferro e/ou alumínio, nas mesmas condições (Weaver e Ritchie, 1994).

\subsection{Precipitação de fósforo com magnésio}

Alternativamente as reações anteriormente consideradas, o uso de sais de magnésio é uma outra possibilidade para a remoção de fósforo de águas residuárias (Equação 3):

$$
\mathrm{HPO}^{2-}+\mathrm{Mg}^{2+}+\mathrm{NH}_{4}^{+}+6 \mathrm{H}_{2} \mathrm{O} \leftrightarrow \mathrm{MgNH}_{4} \mathrm{PO}_{4} \cdot 6 \mathrm{H}_{2} \mathrm{O}+\mathrm{H}^{+}
$$

Estas reações ocorrem sob condições alcalinas, originando um precipitado denominado de estruvita $\left[\mathrm{MgNH}_{4} \mathrm{PO}_{4} \cdot 6 \mathrm{H}_{2} \mathrm{O}\right]$ capaz de remover simultaneamente $\mathrm{NH}_{4}{ }^{+}$e $\mathrm{PO}_{4}{ }^{-3}$ dos efluentes (De-Bashan e Bashan, 2004). A estruvita é uma substância cristalina composta de magnésio e amônia e fósforo em concentrações molares equivalentes (Liu et al., 2011). Devido à sua baixa solubilidade em soluções de $\mathrm{pH}$ neutro, a estruvita é considerada um fertilizante de libertação lenta de excelente desempenho agrícola (Shu et al., 2006).

Similarmente ao uso de sais de cálcio, os sais de magnésio apresentam desempenho inferior ao ferro e alumínio, além de necessitar de condições específicas para a ocorrência da reação já que a proporção molar de $\mathrm{Mg}^{2+}: \mathrm{NH}_{4}{ }^{+}: \mathrm{PO}_{4}{ }^{3-}$ deve estar em torno de $1: 1: 1$ (Liu et al., 2011), exigência que limita severamente sua aplicação industrial.

\section{REMOÇÃO DE FÓSFORO POR ADSORÇÃO}

Tecnologias de adsorção, baseadas na acumulação de fósforo na interface entre duas fases (água contaminada e adsorvente sólido) são uma possibilidade para o gerenciamento deste elemento (Ali et al., 2012). O mecanismo de remoção está baseado no desequilíbrio das forças de atração, que são responsáveis pela adsorção. Desta forma, a adsorção física pode ocorrer a partir das interações de Van der Waals universais, ou através de ligações químicas entre a molécula de adsorvente e o poluente adsorvido (Dabrowski, 2001).

Uma série de materiais adsorventes tem sido extensivamente investigada para uso no controle da poluição de águas residuais. Alguns dos mais importantes incluem carbono ativado, alumina ativada, zeólitas, polímeros sintéticos e adsorventes à base de sílica. Porém essas substâncias adsorventes têm aplicação limitada devido ao seu custo elevado (Tchobanoglous et al., 2003). Neste sentido, o esforço de pesquisa e desenvolvimento (P\&D) tem sido direcionado a consolidação de adsorventes de baixo custo (Bhatnagar e Sillanpää, 2010). De acordo com Ali et al. (2012), adsorventes alternativos podem ser preparados a partir de uma ampla variedade de matérias-primas, abundantes e baratas, com elevado teor de carbono orgânico e baixo conteúdo de partículas, que podem ser facilmente ativados. Entre os materiais de maior potencial de exploração citam-se os aluminosilicatos e os resíduos agrícolas a base de cascas de arroz, trigo, amêndoas, café e coco.

Os desempenhos são elevados, geralmente na ordem de $90 \%$ de eficiência de remoção. Além disso, considera-se um processo simples e de fácil operação. Os equipamentos para a 
adsorção consistem normalmente em reatores de leito recheado, operados em regime hidráulico de fluxo pistonado (Özacar e Sengil, 2003; Kioussis et al., 2000).

\section{REMOÇÃO BIOLÓGICA APRIMORADA DE FOSFATO (EBPR)}

Os sistemas EPBR, do inglês, Enhanced Biological Phosporus Removal, baseiam no uso de um grupo específico de bactérias, chamados de organismos acumuladores de fosfato (PAO), que assimilam o fosfato total dissolvido presente nas águas residuárias sob condições alternadas de anaerobiose e aerobiose (Yuan et al., 2012).

A alternância em relação à disponibilidade do elemento oxigênio faz com que os micro-organismos selecionados assimilem uma quantidade de fósforo superior à requerida nos processos metabólicos usuais. Neste sentido, sob condições anaeróbias os micro-organismos consomem a matéria orgânica facilmente biodegradável, armazenando energia na forma de polihidroxialcanoatos intracelulares (PHAs) com paralela liberação de fosfato para o efluente (Choi et al., 1996). Na sequência da reação, sob condições aeróbias os PHAs armazenados são oxidados para produzir energia para a captação de fosfato, reposição de glicogênio e crescimento celular, resultando na conversão do fosfato presente no efluente em biomassa microbiana (Gebremariam et al., 2011). Como a quantidade de fósforo absorvido pelos PAOs é superior à quantidade liberada anaerobiamente, o processo resulta na bioconversão do fósforo diluído no efluente para uma forma mais concentrada nos agregados microbianos (Yuan et al., 2012).

Biologicamente, a espécie dominante entre as PAOs é a Candidatus Accumulibacter phosphatis (Accumulibacter), embora sua ocorrência nos sistemas de tratamento esteja normalmente relacionada a consórcios bacterianos, em função da dificuldade de produzir a manter cultivos axênicos. Adicionalmente, também são consideradas como PAOs as bactérias do gênero Tetrasphaera (Actinobacteria), abundantemente encontradas em reatores EBPR de larga escala (Carvalho et al., 2007). Por outro lado, deve-se considerar a ocorrência de grupos microbianos acumuladores de glicogênio, que são capazes de se proliferar nas mesmas condições dos PAOs. Esses micro-organismos além de não contribuírem para a conversão do fosfato total dissolvido das águas residuárias, competem pelas fontes de carbono facilmente assimiláveis, restringindo o desempenho dos sistemas (Oehmen et al., 2007).

Tecnologicamente, as configurações de biorreatores EBPR mais comumente empregadas consistem em um sistema sequencial composto por um reator anaeróbio, um reator aeróbio e um tanque de clarificação com reciclo de células (Tchobanoglous et al., 2003). Esses sistemas têm sido empregados eficientemente em escala industrial no tratamento de esgotos domésticos além de diversas águas residuárias industriais, com eficiências de remoção variando entre 75 a $99 \%$, em uma faixa de carga de fósforo total de $25 \mathrm{mgL}^{-1}$ a $125 \mathrm{mgL}^{-1}$ (Lemaire et al., 2009; Mulkerrins et al., 2004; Kishida et al., 2009).

Como resultado desta conversão, há a produção de elevados volumes de lodo, rico em fósforo, que necessita de gerenciamento como um resíduo sólido. As principais abordagens incluem a aplicação direta de biossólidos para o solo como fertilizante, a liberação do fósforo do lodo por métodos biológicos seguido de métodos químicos (precipitação ou adsorção) e a liberação do fósforo de lodo por métodos termoquímicos, seguido por utilização dos resíduos ou ainda passando por um tratamento adicional para a recuperação. No entanto, a recuperação do fósforo destes lodos apresenta ainda desafios técnicos e econômicos que limitam o seu reúso (Yuan et al., 2012). 


\section{REMOÇÃO DE FÓSFORO UTILIZANDO MACRÓFITAS}

A utilização de plantas aquáticas tem se destacado entre as tecnologias de tratamento de efluentes, porque além da remoção de nutrientes das águas residuárias, também fornece uma maneira potencialmente lucrativa de reciclar os nutrientes através da produção de uma variedade de produtos de valor agregado a partir da biomassa pós-colheita (Xu e Shen, 2011).

O sistema mais utilizado é conhecido como wetland, que consiste, basicamente, em tanques de areia com macrófitas enraizadas, por onde flui a água residuária a ser tratada. Além de macrófitas enraizadas utilizadas nestas estruturas, algumas macrófitas flutuantes têm demonstrado eficiência no tratamento de efluentes (Mohedano et al., 2012). Cheng e Stomp (2009) afirmam que as plantas flutuantes respondem de maneira eficaz na remoção de nutrientes quando comparadas às enraizadas, pois estas atuam no sedimento enquanto que as flutuantes retiram os nutrientes diretamente do corpo d'água. Ainda em comparação com outras plantas aquáticas, macrófitas flutuantes são menos sensíveis a baixas temperaturas, níveis elevados de nutrientes, pragas e doenças (Iqbal, 1999).

Dentre as espécies de macrófitas flutuantes mais utilizadas destacam-se a Eichhorniacrassipes conhecidas como aguapé e as espécies do gênero Lemna spp. denominadas comumente de lentilhas d'água (Shilton et al., 2012). Segundo Tchobanoglous et al. (2003) os sistemas de tratamento de efluentes com lentilhas d'água, podem ser realizados em lagoas convencionais de estabilização, sendo que a remoção de fósforo nesses sistemas é predominantemente devido ao crescimento da biomassa.

Vários pesquisadores realizaram estudos sobre a utilização potencial de macrófitas no tratamento de águas residuais, especialmente para a remoção de nutrientes. Para este fim, Mohedano et al. (2012) relatou o excelente desempenho da Lemna valdivianana para remoção de nutrientes a partir de resíduos de aquicultura, com eficiência de remoção de fósforo de 94\%. Xu e Shen (2011) demonstraram o potencial de Spirodela oligorrhiza, obtendo remoções de até $89,4 \%$ de fósforo a partir de efluentes de dejetos de suínos.

Apesar dos elevados desempenhos, as tecnologias envolvendo macrófitas requerem um rigoroso manejo e monitoramento dos sistemas, principalmente no que diz respeito à constante remoção da biomassa, pois com envelhecimento das folhas os nutrientes absorvidos podem retornar a coluna d'água. Além disso, os problemas relacionados a esse tipo de tratamento também se referem à baixa tolerância a águas residuárias com elevada carga orgânica, onde há a necessidade de um tratamento secundário para a redução da $\mathrm{DBO}$ e ao baixo crescimento da maioria das espécies a baixas temperaturas $\left(0-10^{\circ} \mathrm{C}\right)$ (Cheng e Stomp, 2009).

Todavia, o diferencial do sistema está na geração de diferentes co-produtos, a partir da biomassa pós-colheita. Landesman et al. (2002) determinaram a composição centesimal da biomassa seca de Lemna gibba, obtendo teores de proteínas $(41,7 \%)$, carboidratos $(17,6 \%)$, minerais $(16,2 \%)$ e lipídeos $(4,4 \%)$, que potencializam o reúso da biomassa para a ração animal e produção de bioetanol.

\section{REMOÇÃO DE FÓSFORO POR MICROALGAS}

Microalgas é um termo genérico usado para classificar dez diferentes grupos de micro-organismos aquáticos, o que inclui o Cyanophyta, Chlorarachniophyta, Glaucophyta, Euglenophyta, Cryptophya, Prymnesiophyta, Dinophyta, Ochrophyta, Rhodophyta e Chlorophyta. Alguns destes grupos se destacam sob o aspecto de exploração biotecnológica, como as cianobactérias (Cyanophyta), as clorofíceas (Chlorophyta) e as diatomáceas (Ochrophyta) (Mata et al., 2010), apresentando potencial para uso como biocatalisadores em processos de conversão biológica de fósforo. 
Estes micro-organismos são metabolicamente versáteis, uma vez que podem utilizar até três metabolismos paralelos para a obtenção de energia, a fotossíntese, a respiração e a fixação de nitrogênio, o que determina vantagens para uso no tratamento secundário e terciário de águas residuárias (Queiroz et al., 2013).

Independente da rota metabólica adotada, a conversão de fósforo por microalgas ocorre por este elemento ser essencial para síntese celular de fosfolipídios, nucleotídeos e ácidos nucléicos. Tipicamente as células destes organismos contem aproximadamente $1 \%$ de fósforo em base seca, embora em certas condições, haja evidências que as estes organismos sejam capazes de retirar das águas residuárias quantidades excedentes de fósforo para posterior utilização. Este fósforo extra é estocado na forma de fosfato para uso como recurso interno quando as condições externas de fósforo são limitantes. Adicionalmente, deve-se considerar a possibilidade de remoção passiva de fósforo, através da adsorção na biomassa, como um mecanismo complementar de remoção (Vieira et al., 2012a).

Além das elevadas eficiências de remoção de fósforo, que atingem valores na ordem de 100\% (Queiroz et al., 2013; Vieira et al., 2012b), deve-se considerar a possibilidade da remoção simultânea de material orgânico e nitrogênio das águas residuárias, em uma única etapa (Jacob-Lopes et al., 2013), além do potencial aproveitamento da biomassa gerada na forma de compostos intermediários e/ou produtos finais de valor agregado (Spolaore et al., 2006).

Os sistemas de tratamento incluem biorreatores fotossintéticos e heterotróficos. Os fotobiorreatores consistem em vasos de reação iluminados capazes de conduzir reações fotossintéticas (Jacob-Lopes et al., 2007). Dentre as inúmeras configurações passíveis de uso, os tanques ovais dotados de misturadores mecânicos, chamados de raceways são os sistemas de maior aplicabilidade. Estes sistemas abertos apresentam inúmeras limitações biológicas como a estabilidade dos organismos, taxas de conversão, utilização da energia luminosa, questões de sazonalidade e recuperação da biomassa (Queiroz et al., 2007). Em função destas limitações, sistemas fechados têm sido propostos, incluindo principalmente os reatores tubulares e de coluna de bolhas. Estas configurações, no entanto, são atualmente limitadas por aspectos de engenharia de escala.

Alternativamente, biorreatores heterotróficos microalgais, que são sistemas independentes da energia luminosa, operando em completo escuro, têm sido propostos como uma alternativa para contornar as limitações dos sistemas fotossintéticos (Perez-Garcia et al., 2011). Estes sistemas são de fácil escalonamento e apresentam como principal vantagem à possibilidade de remover simultaneamente outros poluentes além do fósforo.

\section{FERTIRRIGAÇÃO}

As fragilidades técnico-econômicas evidenciadas atualmente na maioria dos processos de tratamento de fósforo, associadas ao valor deste elemento como fertilizante agrícola têm pressionado o seu reúso através de técnicas de fertirrigação. Esta tecnologia é baseada no aporte simultâneo de água e nutrientes, que são absorvidos controladamente pelas culturas agrícolas. Sua relevância torna-se ainda mais evidente, principalmente em regiões com baixos índices pluviométricos anuais (Setti et al., 2001).

A agência de proteção ambiental americana (USEPA, 1992) estabelece diretrizes para o emprego seguro desta tecnologia, dividindo o reúso em categorias de uso urbano, agrícola (alimentos e não alimentos), recreação, construção civil e industrial.

Há, no entanto, limitações de ordem sanitária e ambiental, que limitam o uso direto das águas residuárias. Neste sentido, níveis diferenciados de tratamento são requeridos em função do tipo do reúso. Evidentemente que o reúso agrícola para produção de alimentos é a 
categoria de maior nível de exigência, requerendo um tratamento terciário seguido de desinfeção para liberação de uso (Armon et al., 1994; Pedrero et al., 2010).

Deve-se considerar ainda, questões relacionadas a alterações físico-químicas dos solos, uma vez que salinidade, toxidade a íons específicos e aporte inadequado de nutrientes podem limitar a fertilidade dos solos agrícolas (Hussaine e Al-Saati, 1999; Hamilton et al., 2005).

As principais técnicas de fertirrigação adotadas incluem a infiltração, por inundação ou sulcos, e ainda a aspersão, por aspersores semi-fixos e canhões hidráulicos (Tchobanoglous et al., 2003).

Economicamente, o aspecto positivo está relacionado à redução no uso de fertilizantes químicos, embora os custos do tratamento inicial, associados às despesas com o transporte e distribuição das águas residuárias limitem em muitos casos a viabilidade do processo (Hespanhol, 2002).

\section{CONSIDERAÇÕES FINAIS - APLICABILIDADE DOS PROCESSOS}

A contenção da poluição pelas diferentes formas fosforadas passíveis de ocorrência nas águas residuárias tem sido considerada como a principal limitação das atuais estações de tratamento de efluentes.

A falta de tecnologias técnico-economicamente adequadas ao uso nas escalas requeridas levou a legislação ambiental a desenvolver diretrizes capazes de amenizar o não cumprimento com os padrões de emissão (Brasil, 2005; Rio Grande do Sul, 2006).

Desta forma, além dos limites de emissão de fósforo total, fixados entre 1 a $4 \mathrm{~g} \mathrm{~m}^{-3}$, como uma função primária da vazão de operação da indústria, há a possibilidade de enquadramento na chamada eficiência mínima, em casos em que não se atinge as concentrações estabelecidas e há a permissão da disposição do efluente acima do valor fixado, desde que fique comprovada a eficiência de remoção (\%) normalmente de $75 \%$ para fósforo total. Esta possibilidade suplementar decorre do menor nível tecnológico atualmente existente para mitigação destas formas poluentes. A Tabela 1 sumariza os principais aspectos das tecnologias de gerenciamento de fósforo disponíveis para aplicação industrial imediata, além dos processos em fase de pesquisa e desenvolvimento (P\&D).

Finalmente, se considerarmos os custos de tratamento, a agência de proteção ambiental americana (USEPA, 2013) estima valores entre US\$ 50 a 212 por kilograma de fósforo total removido de águas residuárias através de técnicas de precipitação química, o que reflete em substanciais aportes financeiros requeridos pelas estações de tratamento de efluentes para a contenção deste elemento.

Ao simularmos, por exemplo, uma indústria de grande porte $\left(10.000 \mathrm{~m}^{3} /\right.$ dia $)$ que gera uma água residuária com concentrações de fósforo total na ordem de $10 \mathrm{mg} / \mathrm{L}$, os custos operacionais de tratamento de fósforo estariam estimados em um montante superior a US\$5.000.000/ano. Neste caso em específico, seriam tratados 33,6 toneladas de fósforo por ano (considerando uma operação industrial de 336 dias/ano).

Estes elevados valores dispendidos, no entanto, omitem o verdadeiro potencial de exploração deste elemento, pois ao consideramos a possibilidade de reúso deste elemento na forma de fósforo fertilizante é possível estimar um valor potencial na ordem de US\$ 33.600.000/ano, considerando a recuperação e comercialização das 33,6 toneladas geradas pela indústria e os valores equivalentes de fosfato de amônio no mercado internacional (US\$1,000/ton).

Esta análise comparativa evidencia que no médio-longo prazo, será imperativa a consolidação de tecnologias sustentáveis para o gerenciamento deste elemento, através de processos que equilibrem os vetores meio ambiente, sociedade e economia. 
Tabela 1 Sumário das principais tecnologias para remoção de fósforo de águas residuárias.

\begin{tabular}{|c|c|c|c|c|}
\hline Tecnologia & $\begin{array}{l}\text { Faixas de } \\
\text { atuação } \\
(\mathrm{mgP} / \mathrm{L})\end{array}$ & $\begin{array}{l}\text { Eficiências de } \\
\text { remoção } \\
(\%)\end{array}$ & Vantagens & Desvantagens \\
\hline Precipitação química & $>50$ & $60-95$ & $\begin{array}{l}\text { Facilidade de operação } \\
\text { Robustez }\end{array}$ & $\begin{array}{l}\text { Elevado custo operacional dos } \\
\text { coagulantes } \\
\text { Produção de lodo químico que necessita } \\
\text { de gerenciamento }\end{array}$ \\
\hline Adsorção & $0,5-50$ & $75-90$ & $\begin{array}{l}\text { Facilidade de operação } \\
\text { Eficiência de remoção independente da } \\
\text { concentração de fósforo no efluente }\end{array}$ & $\begin{array}{l}\text { Elevado custo operacional dos } \\
\text { adsorventes }\end{array}$ \\
\hline $\begin{array}{l}\text { Remoção biológica } \\
\text { aprimorada }\end{array}$ & $10-125$ & $75-98$ & $\begin{array}{l}\text { Ausência de produtos químicos } \\
\text { Remoção paralela de nitrogênio }\end{array}$ & $\begin{array}{l}\text { Complexidade operacional } \\
\text { Produção elevada de lodo biológico } \\
\text { Difícil recuperação do fósforo do lodo }\end{array}$ \\
\hline Wetlands & $>0,3$ & $65-99$ & $\begin{array}{l}\text { Elevada eficiência de remoção } \\
\text { Reúso da biomassa como fonte de } \\
\text { proteína e carboidratos }\end{array}$ & $\begin{array}{l}\text { Complexidade operacional } \\
\text { Baixa tolerância a elevadas cargas } \\
\text { orgânicas } \\
\text { Sensibilidade a baixas temperaturas }\end{array}$ \\
\hline Biorreatores microalgais & $>0,1$ & $85-100$ & $\begin{array}{l}\text { Elevada eficiência de remoção } \\
\text { Remoção paralela de matéria orgânica e } \\
\text { nitrogênio Reúso da biomassa como } \\
\text { fonte de proteína, gordura e pigmentos } \\
\text { naturais }\end{array}$ & $\begin{array}{l}\text { Dificuldade de escalonamento } \\
\text { Instabilidade operacional (aspectos } \\
\text { biológicos e físicos) }\end{array}$ \\
\hline Fertirrigação & Não se aplica & 100 & $\begin{array}{l}\text { Reúso da água } \\
\text { Reúso de compostos fertilizantes }\end{array}$ & $\begin{array}{l}\text { Potenciais dados sanitários e ambientais } \\
\text { Complexa logística de distribuição }\end{array}$ \\
\hline
\end{tabular}




\section{AGRADECIMENTOS}

Ao Conselho Nacional de Desenvolvimento Científico e Tecnológico (CNPq), processo 470347/2012-0.

\section{REFERÊNCIAS BIBLIOGRÁFICAS:}

ALI, I.; ASIM, M.; KHAN, T.A. Low cost adsorbents for the removal of organic pollutants from wastewater. Journal of Environmental Management, v. 130, p. 170-183, 2012. http://dx.doi.org/10.1016/j.jenvman.2012.08.028

ARMON, R.; DOSORETZ, C. G.; AZOV, Y.; SHELEF, G. Residual contamination on crops irrigated with effluent of different qualities: a field study. Water Science and Technology, v. 30, p. 239-248, 1994.

BHATNAGAR, A.; SILLANPÄÄ, M. Utilization of agro-industrial and municipal waste materials as potential adsorbents for water treatment - a review. Chemical Engineering Journal, v. 157, p. 277-296, 2010. http://dx.doi.org/10.1016/j.cej.2010.01.007

BRASIL. Conselho Nacional do Meio Ambiente - CONAMA. Resolução n ${ }^{\circ}$ 357, de 17 de março de 2005. Dispõe sobre a classificação dos corpos de água e diretrizes ambientais para o seu enquadramento, bem como estabelece as condições e padrões de lançamento de efluentes. Brasília, 2005. Disponível em: http://www.mma.gov.br/port/conama/res/res05/res35705.pdf. Acesso em: 15 ago. 2014.

CARVAlHO, G.; LEMOS, P. C.; OEHMEN, A.; REIS, M. A. M. Denitrifying phosphorus removal: linking the process performance with the microbial community structure. Water Research, v. 41, p. 4383-4396, 2007. http://dx.doi.org/10.1016/j.watres.2007.06.065

CHENG, J. J.; STOMP, A. M. Growing duckweed to recover nutrients from wastewaters and for production of fuel ethanol and animal feed. CLEAN: Soil, Air Water, v. 37, p. $17-$ 26, 2009. http://dx.doi.org/10.1002/clen.200800210

CHOI, Y.; SHIN, E. B.; LEE, Y. D. Biological phosphorus removal from wastewater in a single reactor combining anaerobic and aerobic conditions. Water Science Technology, v. 34, p. 179-186, 1996. http://dx.doi.org/10.1016/0273-1223(96)00508-2

CORDELL, D.; DRANGERT, J. O.; WHITE, S. The story of phosphorus: global food security and food for thought. Global Environmental Change, v. 19, p. 292-305, 2009. http://dx.doi.org/10.1016/j.gloenvcha.2008.10.009

DABROWSKI, A. Adsorption - from theory to practice. Advances in Colloid and Interface Science, v. 93, p. 135-224, 2001. http://dx.doi.org/10.1016/S0001-8686(00)00082-8

DE-BASHAN, L. E.; BASHAN, Y. Recent advances in removing phosphorus from wastewater and its future use as fertilizer (1997-2003). Water Research, v. 38, p. 4222-4246, 2004. http://dx.doi.org/10.1016/j.watres.2004.07.014

ELSER, J. J. Phosphorus: a limiting nutrient for humanity? Current Opinion in Biotechnology, v. 23, p. 933-938, 2012. http://dx.doi.org/10.1016/j.copbio.2012.03.001

FYTIANOS, K.; VOUDRIAS, E.; RAIKOS, N. Modelling of phosphorus removal from aqueous and wastewater samples using ferric iron. Environmental Pollution, v. 101, p. 12-130, 1998. http://dx.doi.org/10.1016/S0269-7491(98)00007-4 
GEBREMARIAM S. Y.; BEUTEL M. W.; CHRISTIAN D.; HESS T. F. Research advances and challenges in the microbiology of enhanced biological phosphorus removal - a critical review. Water Environment Research, v. 83, p. 195-219, 2011. http://dx.doi.org/10.2175/106143010X12780288628534

HAMILTON, A. J.; BOLAND, A. M.; STEVENS, D.; KELLY, J.; RADCLIFFE, J.; ZIEHRL, A. et al. Position of the Australian horticultural industry with respect to the use of reclaimed water. Agricultural Water Management, v. 71, p. 181-209, 2005. http://dx.doi.org/10.1016/j.agwat.2004.11.001

HESPANHOL, I. Potencial de reuso de água no Brasil: agricultura, indústria, municípios, recarga de aquíferos. Revista Brasileira de Recursos Hídricos, v. 7, p. 75-95, 2002.

HUSSAIN, G.; AL-SAATI, A. J. Wastewaterqualityand its reuse in agriculture in Saudi Arabia. Desalination, v. 123, p. 241-251, 1999. http://dx.doi.org/10.1016/S00119164(99)00076-4

IQBAL, S. Duckweed aquaculture: potentials possibilities and limitations for combined wastewater treatment and animal feed production in developing contries. Switzerland: Sandec, 1999. Online. Disponível em: <http://www.eawag.ch/forschung/sandec /publikationen/wra/dl/duckweed.pdf> Acesso em set. 2012.

JACOB-LOPES, E.; SANTOS, A. M.; RODRIGUES, D. B.; LUI, M. C. Y.; SOUZA, C.; PRUDENTE, D.; ZEPKA, L. Q. Bioprocesso de conversão de efluentes híbridos, biorreator heterotrófico, bioprodutos e seus usos. BR n. PI10201302047, 19 ago. 2013.

JACOB-LOPES, E.; ZEPKA, L. Q.; PINTO, L. A. A.; QUEIROZ, M. I. Characteristics of thinlayer drying of the cyanobacteriumAphanothece microscopic Nägeli. Chemical Engineering and Processing, v. 46, p. 63-69, 2007. http://dx.doi.org/doi: 10.1016/j.cep.2006.04.004

KIOUSSIS, D. R.; WHEATON, F. W.; KOFINAS, P. Reactive nitrogen and phosphorus removal from aquaculture wastewater effluents using polymer hydrogels. Aquacultural Engineering, v. 23, p. 315-332, 2000. http://dx.doi.org/10.1016/S0144-8609(00)00058-3

KISHIDA, N.; TSUNEDA, S.; KIM, J.; SUDO, R. Simultaneous nitrogen and phosphorus removal from high-strength industrial wastewater using aerobic granular sludge. Journal Environmental Engineering, v. 135, p. 153-158, 2009. http://dx.doi.org/10.1061/(ASCE)0733-9372(2009)135:3(153)

LANDESMAN, L.; CHANG, J.; YAMAMOTO, Y.; GOODWIN, J. Nutritional value of wastewater grown duckweed for fish and shrimp feed. World Aquaculture, v. 33, p. 3940, 2002. http://dx.doi.org/10.13031/2013.9953

LEMAIRE, R.; YUAN, Z.; BERNET, N.; MARCOS, M.; YILMAZ, G.; KELLER, J. A sequencing batch reactor system for high-level biological nitrogen and phosphorus removal from abattoir wastewater. Biodegradation, v. 20, p. 339-350, 2009. http://dx.doi.org/10.1007/s10532-008-9225-z

LIU, Y. H.; KWAG, J. H.; KIM, J. H.; RA, C. S. Recovery ofnitrogenandphosphorusbystruvitecrystallizationfromswinewastewater. Desalination, v. 277, p. 364-369, 2011. http://dx.doi.org/10.1016/j.desal.2011.04.056 
MAJED, N.; LI, Y.; GU, A. Z. Advances in techniques for phosphorus analysis in biological sources. Current Opinion in Biotechnology, v. 23, p. 1-8, 2012. http://dx.doi.org/10.1016/j.copbio.2012.06.002

MATA, T. M.; MARTINS, A. A.; CAETANO, N. S. Microalgae for biodiesel production and other application: A review. Reviews of Sustainable Energy, v. 14, p. 217-232, 2010. http://dx.doi.org/10.1016/j.rser.2009.07.020

MOHEDANO, R. A.; COSTA, R. H. R.; TAVARES, F. A.; BELLI FILHO, P. High nutrient removal rate from swine wastes and protein biomass production by full-scale duckweed ponds. Bioresource Technology, v. 112, p. 98-104, 2012.

http://dx.doi.org/10.1016/j.biortech.2012.02.083

MORSE, G. K.; BRETT, S. W.; GUY, J. A.; LESTER, J. N. Review: phosphorus removal and recovery technologies. The Science of the Total Environment, v. 212, p. 69-81, 1998. http://dx.doi.org/10.1016/S0048-9697(97)00332-X

MULKERRINS, D.; O’CONNOR, E.; LAWLEE, B.; BARTON, P.; DOBSON, A. Assessing the feasibility of achieving biological nutrient removal from wastewater at an Irish food processing factory. Bioresource Technology, v. 91, p. 207-214, 2004. http://dx.doi.org/10.1016/S0960-8524(03)00173-1

OEHMEN, A.; LEMOS, P. C.; CARVALHO, G.; YUAN, Z.; KELLER, J.; BLACKALL, L. L. et al. Advances in enhanced biological phosphorus removal: from micro to macro scale. Water Research, v. 41, p. 2271-2300, 2007. http://dx.doi.org/10.1016/j.watres.2007.02.030

ÖZACAR, M.; ŞENGIL, I. A. Enhancing phosphate removal from wastewater by using polyelectrolytes and clay injection. Journal of Hazardous Materials, v. 100, p. 131146, 2003. http://dx.doi.org/10.1016/S0304-3894(03)00070-0

PEDRERO, F.; KALAVROUZIOTIS, L.; ALARCÓN, J. J.; KOUKOULAKIS, P.; ASANO, T. Use of treated municipal wastewater in irrigated agriculture - Review of some practices in Spain and Greece. Agricultural Water Management, v. 97 p. 1233-1241, 2010. http://dx.doi.org/10.1016/j.agwat.2010.03.003

PEREZ-GARCIA, O.; ESCALANTE, F. M. E.; DE-BASHAN, L. E.; BASHAN, Y. Heterotrophic cultures of microalgae: metabolism and potential products. Water Research, v. 45, p. 11-36, 2011. http://dx.doi.org/10.1016/j.watres.2010.08.037

PRATT, C.; PARSONS, S. A.; SOARES, A.; MARTIN, B. D. Biologically and chemically mediated adsorption and precipitation of phosphorus from wastewater. Current opinion in Biotechnology, v. 23, p. 890-896, 2012.

http://dx.doi.org/10.1016/j.copbio.2012.07.003

QUEIROZ, M. I.; HORNES, M.; MANETTI, A. G. S.; ZEPKA, L. Q.; JACOB-LOPES, E. Fish processing wastewater as a platform of the microalgal biorefineries. Biosystems Engineering, v. 115, p. 195-202, 2013. http://dx.doi.org/10.1016/j.biosystemseng.2012.12.013.

QUEIROZ, M. I.; JACOB-LOPES, E.; ZEPKA, L. Q.; BASTOS, R. G.; GOLDBECK, R. The kinetics of the removal of nitrogen and organic matter from parboiled rice effluent by cyanobacteria in a stirred batch reactor. Bioresource Technology, v.98, p. 2163-2169, 2007. http://dx.doi.org/10.1016/j.biortech.2006.08.034 
RIO GRANDE DO SUL. Secretaria do Meio Ambiente - CONSEMA. Resolução n 128/2006. Dispõe sobre a fixação de padrões de emissão de efluentes líquidos para fontes de emissão que lancem seus efluentes em águas superficiais do estado do Rio Grande do Sul. Porto Alegre, 2006. Diário Oficial [do] Estado do Rio Grande do Sul, 07 dez. 2006.

RITTMANN, B. E.; MAYER, B.; WESTERHOFF, P.; EDWARDS, M. Capturing the lost phosphorus. Chemosphere, v. 84, p. 846-853, 2011. http://dx.doi.org/10.1016/j.chemosphere.2011.02.001.

SETTI, A. A.; LIMA, J. E. F. W.; CHAVES, A. G. M.; PEREIRA, I. C. Introdução ao gerenciamento de recursos hídricos. Brasília: ANA, 2001.

SHILTON, A.; POWELL, N.; GUIEYSSE, B. Plant based phosphorus recovery from wastewater via algae and macrophytes. Current Opinion in Biotechnology, v. 23, p. 884-889, 2012. http://dx.doi.org/10.1016/j.copbio.2012.07.002

SHU, L.; SCHNEIDER, P.; JEGATHEESAN, V.; JOHNSON, J. An economic evaluation of phosphorus recovery as struvite from digester supernatant. Bioresource Technology, v. 97, p. 2211-2216, 2006. http://dx.doi.org/10.1016/j.biortech.2005.11.005

SPOLAORE, P.; JOANNIS-CASSAN, C.; DURAN, E.; ISAMBERT, A. Commercial Applications of Microalgae. Journal of Bioscience and Bioengineering, v. 101, p. 8796, 2006. http://dx.doi.org/10.1263/jbb.101.87

SZÖGI, A. A.; VANOTTI, M. B; HUNT, P. G. Dewatering of phosphorus extracted from liquid swine waste. Bioresource Technology, v. 97 p. 183-190, 2006. http://dx.doi.org/10.1016/j.biortech.2005.02.001

TCHOBANOGLOUS, G.; BURTON, F. L.; STENSEL, D. Wastewater engineering, treatment and reuse. New York: McGraw-Hill, 2003. 1815p.

UNITED STATES. Environmental Protection Agency - USEPA. Environmental equity: reducing risk for all communities. Washington, DC, 1992.

UNITED STATES. Environmental Protection Agency - USEPA. Technical support document: cost estimate of phosphorus removal at wastewater treatment plants. Washington, DC, 2013.

VIEIRA, J. G.; MANETTI, A. G. S.; JACOB-LOPES, E.; QUEIROZ, M. I. Uptake of phosphorus from dairy wastewater by heterotrophic cultures of cyanobacteria. Desalination and Water Treatment, v. 40, p. 1-3, 2012a. http://dx.doi.org/10.1080/19443994.2012.671249

VIEIRA, J. G.; JACOB-LOPES, E.; MANETTI, A. G. S.; QUEIROZ, M. I. Influência da temperatura na remoção de fosfato por microalgas em biorreatores heterotróficos. Revista Ambiente \& Água, v. 7, p. 101-109, 2012b. http://dx.doi.org/10.4136/ambiagua. 856

WEAVER, D. M.; RITCHIE, G. S. P. Phosphorus removal from piggery effluents PF varying quality using lime and physico-chemical treatment methods. Environmental Pollution, v. 84, p. 237-244, 1994. http://dx.doi.org/10.1016/0269-7491(94)90134-1. 
XU, J.; SHEN, G. Growing duckweed in swine wastewater for nutrient recovery and biomass $\begin{array}{llllll}\text { production. Bioresource } & \text { Technology, } & \text { v. 102, p. 848-853, } 2011 .\end{array}$ http://dx.doi.org/10.1016/j.biortech.2010.09.003

YUAN, Z; PRATT, S; BATSTONE, D. J. Phosphorus recovery from wastewater through microbial processes. Current Opinion in Biotechnology, v. 23, p. 878-883, 2012. http://dx.doi.org/10.1016/j.copbio.2012.08.001 